European Child \& Adolescent Psychiatry, in press

UNDER EMBARGO

Do not distribute without author permission

\title{
A RISK ALGORITHM THAT PREDICTS ALCOHOL USE DISORDERS AMONG COLLEGE STUDENTS
}

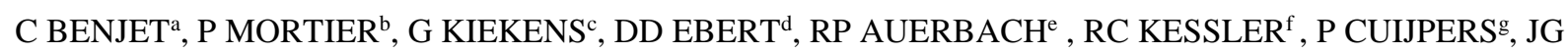

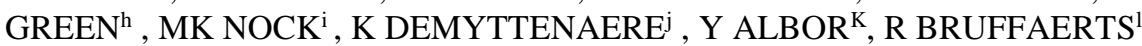

\section{Running head: predicting alcohol use disorders in college students}

${ }^{a}$ Epidemiology and Psychosocial Research, National Institute of Psychiatry Ramón de la Fuente Muñiz, Mexico City, Mexico, ORCID: 0000-0002-4569-6094

${ }^{\mathrm{b}}$ Health Services Research Group, IMIM (Hospital del Mar Medical Research Institute), Barcelona, Spain; CIBER Epidemiología y Salud Pública (CIBERESP), Madrid, Spain; Research Group Psychiatry, Department of Neurosciences, KU Leuven University, Leuven, Belgium, ORCID: 0000-0002-3732-1030

${ }^{\mathrm{c}}$ Center for Public Health Psychiatry, KU Leuven, Leuven, Belgium; School of Psychology, Curtin University, Perth, Australia, ORCID: 0000-0001-8747-3385

${ }^{\mathrm{d}}$ Clinical Psychology and Psychotherapy, Department of Psychology, Friedrich- Alexander- University Erlangen- Nürnberg, Erlangen, Germany, ORCID: 0000-0001-6820-0146

${ }^{\text {e }}$ Department of Psychiatry, Columbia University, New York, United States, 0000-0003-2319-4744

${ }^{\mathrm{f}}$ Harvard Medical School, Department of Health Care Policy, Harvard University, Boston, MA, USA, ORCID: 0000-0003-4831-2305

${ }^{g}$ Department of Clinical, Neuro and Developmental Psychology, Amsterdam Public Health Research Institute, Vrije Universiteit Amsterdam, Amsterdam, the Netherlands, ORCID: 0000-0001-5497-2743

${ }^{\mathrm{h}}$ Wheelock College of Education \& Human Development, Boston University, Boston, MA, USA, ORCID: 00000002-3541-4989

${ }^{\mathrm{I}}$ Department of Psychology, Harvard University, Cambridge, MA, USA, 0000-0001-6508-1145

${ }^{j}$ Universitair Psychiatrisch Centrum; Public Health Psychiatry, KU Leuven, Leuven, Belgium, ORCID: 00000001-5331-487X

${ }^{\text {k }}$ National Institute of Psychiatry Ramón de la Fuente Muñiz, Mexico City \& Universidad Cuauhtémoc Plantel Aguascalientes, Aguascalientes, Mexico, ORCID: 0000-0001-9546-4833

${ }^{1}$ Universitair Psychiatrisch Centrum; Public Health Psychiatry, KU Leuven, Leuven, Belgium, ORCID:_00000002-0330-3694

Correspondence to: Dr. Corina Benjet, Department of Epidemiology and Psychosocial Research, Instituto Nacional de Psiquiatría Ramón de la Fuente Muñiz, Calzada México-Xochimilco 101, San Lornenzo Huipulco, CDMX, 14370, Mexico. Tel: +525541605332. Email: cbenjet@imp.edu.mx 


\begin{abstract}
The first year of college may carry especially high risk for onset of alcohol use disorders. We assessed the oneyear incidence of alcohol use disorders (AUD) among incoming first year students, predictors of AUDincidence, prediction accuracy and population impact. A prospective cohort study of first-year college students (baseline: $\mathrm{N}=5,843$; response rate $=51.8 \%$; 1 -year follow-up: $\mathrm{n}=1,959$; conditional response rate $=41.6 \%$ ) at a large university in Belgium was conducted. AUD were evaluated with the AUDIT and baseline predictors with the Composite International Diagnostic Interview Screening Scales (CIDI-SC). The one-year incidence of AUD was $3.9 \%$ ( $\mathrm{SE}=0.4$ ). The most important individual-level baseline predictors of AUD incidence were being male $(\mathrm{OR}=1.53 ; 95 \% \mathrm{CI}=1.12-2.10)$, a break-up with a romantic partner $(\mathrm{OR}=1.67 ; 95 \% \mathrm{CI}=1.08-2.59)$, hazardous drinking $(\mathrm{OR}=3.36 ; 95 \% \mathrm{CI}=1.31-8.63)$, and alcohol use characteristics at baseline (ORs between 1.29 and 1.38). Multivariate cross-validated prediction (cross-validated AUC $=0.887$ ) show that $55.5 \%$ of incident AUD cases occurred among the $10 \%$ of students at highest predicted risk (20.1\% predicted incidence in this highest-risk subgroup). Four out of five students with incident AUD would hypothetically be preventable if baseline hazardous drinking were to be eliminated along with a reduction of one standard deviation in alcohol use characteristics scores, and another $15.0 \%$ would potentially be preventable if all 12 -month stressful events were eliminated. Screening at college entrance is a promising strategy to identify students at risk of transitioning to more problematic drinking and AUD, thus improving the development and deployment of targeted preventive interventions.
\end{abstract}

Key words: alcohol use disorder; hazardous drinking; university students; risk algorithm; incidence 


\section{INTRODUCTION}

The college years are a developmentally crucial period when students make the transition from late adolescence to emerging adulthood [1]. Apart from personal, social, and intellectual challenges and achievements, the college years are also a peak period for the prevalence of mental disorders [2-3], with around one third of incoming college students meeting criteria for a 12-month mental disorder [4-5]. The prevalence of alcohol use disorders (AUD) among college students is lower than the estimates for some other mental disorders, with 12-month prevalence in students across 21 countries around 5\% [6]. However, the college years, especially the first years, may carry especially high risk for onset of AUD as previous research suggests that up to $70 \%$ of AUD among college students has its onset during and not prior to college entrance [6]. AUD in college is associated with deleterious psychological, social, and physical health consequences [7], including violence [8], accidents and injuries [9], and risky sexual behaviors [10]. Additionally, over 90\% of students with AUD do not perceive their symptoms to be a problem [11]. From a public health perspective, early and accurate identification of students that will make the transition from non-problematic alcohol use to a more severe level of alcohol consumption would facilitate effective deployment of targeted preventive interventions during college and thereby reduce the incidence, prevalence, severity, duration, and consequences of future AUD as well as of mental disorders that are influenced by AUD [12]. To guide allocation of resources and clinical decision-making, colleges need tools that accurately identify students at high risk of transitioning to more problematic drinking and developing AUD. Although there are many studies that estimate the prevalence of AUD in college, studies on the incidence of AUD, and predictors of incidence, among college students are scant. Using longitudinal data from the National Epidemiologic Survey on Alcohol and Related Conditions (NESARC), the incidence of AUD in the general population is estimated to be $1.45 \%$ per year, and approximately $4 \%$ among $20-29$ year olds, but they did not assess incidence specifically for college students who tend to be between 18 and 22 years of age [13].

Given the high availability of internet access and geographic proximity to centralized student services, college campuses may be ideally situated to access large groups of youth for screening and referral to adequate care [14]. Web-based screening provides a practical alternative for students with drinking problems who may be less likely to seek clinical services [15], and further, it may offer personalized feedback and access to online selfhelp interventions [16-17]. Despite these potential advantages, it is currently unknown how many first-year college students effectively make the transition from non-problematic use of alcohol to a more problematic use of alcohol or to AUD, and how accurately these screening tools can identify the high risk students that will make 
the transition, without identifying too many false-positive cases (a concern raised for the screening of suicidal behaviors which limits the feasibility of screening [18]) that would put undue demands on college mental health centers. The development of powerful risk screening algorithms may remediate this.

The present study addresses these shortcomings by examining the first onset of AUD during the college years in a large, longitudinal survey of college students (Leuven College Surveys - see: www.mindmates.be/page.phpid28), a part of the WHO World Mental Health Surveys International College Student initiative (WMH-ICS initiative, see:

http://www.hcp.med.harvard.edu/wmh/college_student_survey.php). We build on earlier work on the development of concentration-of-risk models that estimated and accurately predicted incidence or persistence of mental disorders and self-injurious thoughts and behaviors [19-21]. Consistent with recommendations to develop such risk algorithms to target high-risk individuals for preventive interventions [22-23], we examine the strength of multivariate associations in our model of baseline predictors (socio-demographic factors, drinking patterns at college entrance, traumatic events in childhood or adolescence, stressful events in the 12 months prior to college entrance, and baseline mental disorders and self-injurious thoughts and behaviors) to determine whether a welldefined subset of students at highest risk of incidence of AUD as classified by the empirically determined risk algorithm can be detected.

\section{METHOD}

\section{Procedures}

Full procedures of the LCS have been reported previously [5, 21]. Briefly, the LCS consists of a series of web-based self-report surveys of KU Leuven students. In the academic years 2014-2016, all 13,103 Dutchspeaking incoming freshmen aged 18 years or older were eligible for the baseline survey. A total of 5,844 students completed the baseline survey (51.8\% response rate after adjusting for potential non-participation due to college attrition). Students were contacted for the follow-up survey 12 months after the baseline assessment. A total of 1,959 of the original baseline respondents responded to the follow-up survey (corresponding to a $41.6 \%$ conditional response rate after adjusting for non-participation due to college attrition).

\section{Measures}

Baseline socio-demographic variables. The university's students' administration office provided sociodemographic characteristics, including gender, age, nationality, parents' financial situation, parents' education, 
parental familial composition, university group membership, student situation (full-time student versus other) and type of secondary school education.

Baseline and follow-up drinking patterns and alcohol use disorder was assessed using the Alcohol Use Disorders Identification Test (AUDIT) [24]. The AUDIT was developed to identity hazardous drinking (conceptualized as an alcohol consumption pattern that increases the risk of harmful consequences for the individual or others in the absence of an alcohol use disorder), harmful drinking (conceptualized as alcohol consumption that results in harmful mental and physical health consequences), and alcohol dependence (conceptualized as physiological, psychological and behavioral consequence of prolonged use such as tolerance and withdraw) [25]. The AUDIT consists of a total score (range 0-40) and allows for the calculation of three subscales: the consumption subscale (consisting of three items assessing the frequency and quantity of alcohol use), the dependence subscale (consisting of three items assessing perceived control over drinking, failure to comply to normal expectations due to drinking, and withdrawal symptoms), and the alcohol-related problems subscale (consisting of four items measuring guilt or remorse after drinking, memory lapses after drinking, alcohol-related injuries, and concerns of family, friends or professionals regarding one's drinking). Most research to identify alcohol use problems uses the total score with varying cut-offs [26; 27]. While this version of AUDIT scoring in college students has concordance with clinical diagnosis in the range AUC $=0.85-0.90$ [26], more recent research has suggested more varied and less optimal sensitivity and specificity estimates for females and countries with lower prevalence [27]. For a more fine-grained algorithm that takes into account the dependence subscale as well as the total score, and in line with a prior recommendation [28], we defined alcohol use disorder (AUD) as either a total AUDIT score of 16+ or a total AUDIT score of 8-15 with a score of 4+ on the AUDIT dependence subscale. Those students who did not meet the criteria for AUD were divided into either a hazardous drinking group when they had a total AUDIT score of 8-15 with a score of 0-3 on the AUDIT dependence subscale, or a no hazardous drinking group as having a total AUDIT score of 0-7.

Traumatic experiences in childhood-adolescence (i.e. prior to the age of 17) were assessed using 19 items adapted from the Composite International Diagnostic Interview (CIDI 3.0) childhood section [29], the Adverse Childhood Experience Scale [30], and the Bully Survey [31]. Items assessed parental psychopathology (i.e., any serious mental or emotional problems, substance use problems, suicidal behaviors or death by suicide, criminal activities, or interpersonal violence), physical abuse, emotional abuse, sexual abuse, neglect, bully victimization (i.e., either direct verbal or physical bullying, as well as indirect bullying [e.g., spreading rumors], or cyberbullying), and dating violence. Response options consisted of five-point Likert items ("never", "rarely", 
"sometimes", "often", and "very often"). To obtain dichotomously coded variables (i.e., potential risk factors), cut-off values consisted of "rarely" for all items, except bully victimization which had a cut-off of "sometimes", in line with a previous recommendation [32].

Stressful events experienced in the 12-months before the baseline survey were assessed using items from well-validated screeners [33-35], and included relevant stressful experiences among young adults, including life-threatening illness or injury of a family member or close friend [36], accidents or death of a family member or close friend [37], interpersonal events (e.g., break-up with a romantic partner, serious betrayal by someone other than one's partner) [38], and other stressful experiences (e.g., physical or sexual assault, and legal problems such as time spent in jail [39-41].

Mental disorders in the 12-months before the baseline survey were assessed using the Composite International Diagnostic Interview Screening Scales (CIDI-SC) [42] for major depressive episode, mania/hypomania (broad mania), generalized anxiety disorder (GAD), panic attacks, and drug use disorder (abuse or dependence either on cannabis, cocaine, or any other street drug, or on a prescription drug either used without a prescription or used more than prescribed to get high, buzzed, or numbed out). The CIDI-SC scales have concordance with blinded clinical diagnoses in the range AUC $=0.70-0.78$. Items from the Self-Injurious Thoughts and Behaviors Interview (SITBI - see [43]) assessed 12-month non-suicidal self-injury, suicidal ideation, suicide plans, suicide attempts, and non-suicidal self-injury. We also assessed risk for other mental disorders or symptoms, including lifetime intermittent explosive disorder symptoms, lifetime post-traumatic stress disorder symptoms, and lifetime eating disorder symptoms (using MINI items - see [44]).

\section{Analyses}

Nonresponse propensity weights [45] were created to adjust for potential non-response bias. Multiple imputation by chained equations [46] was used to adjust for survey attrition and within-survey item nonresponse. One case was eliminated for analysis due to missing information on auxiliary variables necessary for calculating non-response weights, resulting in a final sample for analysis of $n=5,843$. Logistic regression analysis examined the strength of individual-level associations (i.e., odds ratios [OR]) between baseline predictor variables and 12 month hazardous drinking or AUD at 12-month follow-up. Two series of models were constructed. A first series predicted AUD at 12-month follow-up among those 5,590 students without AUD at baseline; a second series predicted hazardous drinking or AUD at 12-month follow-up among those 4,381 students without hazardous 
drinking or AUD at baseline. Baseline predictor blocks in the multivariate models included the three AUDIT subscales (including a dummy variable for baseline hazardous drinking in the first series of models), sociodemographic variables, (number of) traumatic experiences in childhood-adolescence, (number of) stressful events experienced in the past 12-months, (number of) lifetime and 12-month mental disorders, and 12-month self-injurious thoughts and behaviors. Individual-level predicted probabilities based on the multivariate equations were created, and area under the curve (AUC) values calculated. The multivariate model with the highest AUC was selected for further evaluation of predictive accuracy. Predicted probabilities were discretized into deciles and cross-classified with observed cases to visualize the concentration of risk associated with high composite predicted probabilities. Sensitivity was defined as the proportion of cases found among pre-defined proportions (e.g., 10\%) of respondents with highest predicted probabilities. Positive Predictive Value (PPV) was defined as the probability of effectively developing the outcome when being among pre-defined proportions (e.g., 10\%) of respondents with highest predicted probabilities. We used the method of leave-one-out crossvalidation [47] to correct for the over-estimation of prediction accuracy when both estimating and evaluating model fit in a single sample. Using summary measures of predicted probabilities calculated using coefficients from the final model, we estimated Potential Impact Fractions (PIF), representing the proportion of outcome cases potentially reduced after a change in the exposure of a related ordinal categorical predictor [48]. We use PIFs instead of the more commonly used Population Attributable Risk Proportion because PIFs are indicated in data where the lowest exposure of a risk factor (i.e. the use of alcohol) is non-zero.

\section{RESULTS}

\section{Description of the sample}

The majority of the sample $(n=5,843)$ was female $(57.0 \%), 18$ years of age $(73.9 \%)$, only few participants $(4.3 \%)$ were of non-Belgian nationality and $17.2 \%$ of the students indicated that they were raised in households with a difficult financial situation. For most students $(62.0 \%)$ both parents had a college education, only a small proportion of students (15.4\%) indicated that neither of their parents had a college education. More than half of all students met criteria for at least one of the three lifetime or five 12-month disorders (57.7\%), and $25.3 \%$ reported exactly one, $15.0 \%$ exactly two, $8.7 \%$ exactly three, and $8.7 \%$ four or more mental disorders. More than half of the sample (58.4\%) reported at least one traumatic experience prior to the age of 17 , with $34.4 \%$ experiencing parental psychopathology as the most reported one, followed by bully victimization 
$(32.4 \%)$. Every second student $(57.6 \%)$ also reported at least one stressful life event in the past year, with the experience of life-threatening illness or injury of a close friend or family member most frequently reported (i.e. $20.6 \%)$.

\section{Incidence of AUD}

Prevalence of hazardous drinking and AUD at baseline and follow-up are shown in table 1. Three findings stand out. First, 12-month prevalence of hazardous drinking and AUD at baseline was 21.6\% and 4.7\%, respectively. Second, persistence of hazardous drinking/AUD among college students (i.e. the proportion of those who meet criteria for hazardous drinking/AUD both at baseline and follow-up) was $60.4 \%$ and $51.5 \%$, respectively. Third, the incidence of AUD among college students is estimated at $3.9 \%(\mathrm{SE}=0.4)$ : an estimated 206 out of the 5,590 college students met criteria for AUD in follow-up while they did not meet criteria for AUD at baseline. More specifically, among those 4,381 students without 12-month hazardous drinking or AUD at baseline, only $1.1 \%$ made the transition to AUD one year later. By comparison, this was $13.6 \%$ among those 1,209 students with 12-month hazardous drinking (but no AUD) at baseline.

\section{TABLE 1 ABOUT HERE}

\section{Bivariate and multivariate predictors of AUD incidence}

Table 2 presents a summary of the baseline variables that significantly predicted AUD at follow-up first among the subsample of students without AUD at baseline and then among only students without hazardous drinking or AUD at baseline. First, among those without AUD at baseline, results from the bivariate analyses show that incidence of AUD at follow-up was associated with baseline hazardous drinking (OR=14.20), alcohol use characteristics (ORs 1.76-2.35), being male (OR=2.67), break-up with a romantic partner in the year prior de college entrance $(\mathrm{OR}=2.05)$, serious betrayal by someone else than a romantic partner $(\mathrm{OR}=1.53)$, and other stressful events in the year prior to college entrance $(\mathrm{OR}=1.89)$. Especially those with two or more stressful events in the past year had higher odds for subsequent onset of AUD (ORs 1.54-2.17). Past 12-month drug use disorder and a lifetime eating disorder were also associated with incident AUD (ORs=5.27 and 1.54 respectively). Second, among students without hazardous drinking or AUD at baseline, bivariate analyses to 
predict hazardous drinking or AUD at 12-month follow-up revealed similar results, though there were a few additional predictors, such as studying biomedical sciences $(\mathrm{OR}=1.21)$ or screening positive for 12-month broad $\operatorname{mania}(\mathrm{OR}=2.31)$.

Table 2 also shows the final selected multivariate models, adjusting for all other risk domains included in those models. AUD at follow-up among those without AUD at baseline (cross-validated AUC $=0.887$ ) was predicted by being male $(\mathrm{OR}=1.53)$, a break-up with a romantic partner in the year prior de college entrance $(\mathrm{OR}=1.67)$, hazardous drinking $(\mathrm{OR}=3.36)$ and alcohol use characteristics at baseline (OR between 1.29 and 1.38). For the more restricted subset of only students without hazardous drinking or AUD at baseline $(\mathrm{AUC}=0.785)$, predictors for hazardous drinking or AUD at 12-month follow-up were similar with a few additional predictors (i.e., studying biomedical sciences, 12-month panic attacks and 12-month broad mania; ORs in the $1.28-2.33$ range).

TABLE 2 ABOUT HERE

\section{Prediction accuracy}

Table 3 shows cross-validated sensitivity and PPV for different proportions of students at highest predicted risk based on the final multivariate models described above. Multivariate cross-validated prediction (cross-validated AUC=0.887) shows that an estimated 55.5\% of incident AUD cases would occur among the $10 \%$ of students at the highest predicted risk and that an estimated $20.1 \%$ of these high-risk students would go on to meet criteria for AUD at follow-up compared to only $3.9 \%$ in the lowest risk subgroup. Among the subset without hazardous drinking or AUD, sensitivity among the $10 \%$ of students at the highest predicted risk was $33.1 \%$ and the positive predicted value $51.3 \%$ versus $16.6 \%$ in the lowest risk subgroup.

TABLE 3 ABOUT HERE

\section{Population impact}

In Table 4 we show adjusted PIFs of baseline predictors based on the final multivariate models described above. Four out of five students with incident AUD would hypothetically be preventable if baseline 
hazardous drinking were to be eliminated along with a reduction of one standard deviation in alcohol use characteristics scores, and another $15.0 \%$ would potentially be preventable if all 12-month stressful events were eliminated. Among the subset without hazardous drinking or AUD at baseline, alcohol use characteristics is attributable to $46.5 \%$ of new onset hazardous drinking/AUD and eliminating all 12-month stressful events would result in another 5.5\% reduction, assuming a full causal relationship.

TABLE 4 ABOUT HERE

\section{DISCUSSION}

\section{Main Findings}

The aim of this study was to develop and evaluate the performance of a risk algorithm that aims to identify students at high risk of new onset AUD during the first year of college. We found a 3.9\% one-year incidence of AUD (in line with the $4.0 \%$ reported for $20-29$ year olds in the general population [13]), that we could predict with a cross-validated AUC of 0.887 with three baseline variables: alcohol consumption scores, male gender, and having broken up with a romantic partner in the 12 months prior to college entrance. Using this algorithm, more than half of incident AUD cases would occur among the $10 \%$ of students at the highest predicted risk. If colleges were to evaluate incoming students with this algorithm and focus intervention on the students in the highest $10 \%$ of predicted risk, they would be targeting more than half of the incident cases. Additionally, a high proportion of AUD incidence was attributable to baseline consumption patterns, which, if reduced by an intervention program during the first year of college, could conceivably decrease AUD incidence by as much as $80.0 \%$. Preventing and/or helping students to cope effectively with stressful life events might also reduce AUD incidence by an additional $15.0 \%$. This is consistent with the findings of Prince, Read and Colder [49] in which relatively small absolute differences in alcohol consumption in the first semester of college predicted large differences in alcohol-related consequences post-graduation. Similarly, Read et al. [50] observed that trauma and post-traumatic stress at matriculation predicted alcohol consequences at the end of the school year. Among the past-year stressful life events assessed, break-up with a romantic partner was the most predictive of increasing risk for AUD. This may be a particularly stressful event for incoming college students given that the transition to college already involves social network changes as many new relationships are formed and need to be balanced with older relationships [51]. In another prospective longitudinal study of 
emerging adults over 18 months, romantic relationship dissolution was associated with increased substance use, including heavy alcohol use [52].

\section{Strengths and limitations}

We present a novel approach to risk prediction by estimating the concentration of risk in different proportions of incoming students at highest predicted risk based on a multivariate model of baseline predictors, and by using PIF to simulate population impact of transitions to more harmful drinking patterns with a large longitudinal sample of college students. The inclusion of baseline AUDIT consumption scores in the prediction algorithm allows a simple cost effective tool for universities to predict transitions to more harmful consumption and eventual AUD. Some limitations, however, should be considered when interpreting the results. First, the response rates were modest (51.8\% at baseline and $41.6 \%$ at follow-up) but consistently higher than those reported in other recent large-scale surveys of college students $(39-44 \%)$ [3, 53]. Additionally, we used cutting edge missing data techniques [46] to increase the representativeness of the data. Because the sample was drawn from one university in Belgium, replicating the findings in other universities represents an important goal for future research. The sample size lacked power to predict AUD exclusively at follow-up among students without hazardous drinking or AUD at baseline. A further limitation is the self-administered self-report assessment of AUD and other mental disorders, rather than a clinician diagnosis based on face-to-face interviews. However, our measures of AUD and other mental disorders were well-validated screening scales used in many prior general populations surveys, and have shown high diagnostic concordance with clinical diagnoses [26, 54]. Finally, while we included a range of baseline predictors (socio-demographic, consumption patterns, life events and mental disorders) there are other predictors which might increase predictive accuracy in the future such as personality traits like sensation-seeking, urgency, and low constraint [11], family history of problem drinking [55], and protective factors (e.g., emotion regulation competencies [56]). However, it will be important for future research to identify the fewest number of predictors possible that provides the optimal level of accuracy to reduce respondent burden and increase the feasibility of evaluating all incoming students.

\section{Clinical and policy implications}

Alcohol use is a large problem across college campuses worldwide. Screening algorithms, such as the one in this study based on integrative multivariate prediction models, may be a useful resource (and one that is 
low-cost and can be easily implemented in the college context) for detecting high-risk students and tailoring interventions to those students based on population-level estimates of the factors that contribute the most to overall incidence, namely baseline consumption patterns and effects of romantic relationship break-up. Thus college mental health prevention efforts could be more selective regarding the students targeted for intervention as well as the exposures targeted, thus optimizing limited resources. Our findings, along with those of others [49], suggest that future AUD can be predicted in the first year of college with reasonable precision and this early detection could be beneficial for college counselors to implement timely preventive strategies. Several promising interventions have been evaluated in this regard for college students [57-59]. However, it may be particularly challenging to get students with alcohol use problems into treatment as prior research has shown that students with AUD are less willing to seek treatment [15] and do not perceive their symptoms to be a problem [11]. Digital risk screeners with subsequent normative feedback, including information about potential preventive options, might be a promising approach to motivate at risk students for preventive interventions [17]. Perhaps interventions that stem from student orientation or activities that address recognition of the problem and are presented less as traditional modes of treatment delivery would be more acceptable for these students [60]. Increasingly, online interventions, which have the potential to reach a greater number of students at a low cost to university administrators, have shown promise in general community and healthcare settings [61-62] though initial results in college students have been mixed [63-65]. The current study provides data to suggest who and what to target in such interventions and the importance of targeting those students during their first year of college.

\section{Acknowledgements}

The Leuven College Survey was carried out in conjunction with the World Health Organization World Mental Health (WMH) survey initiative and is a part of the World Mental Health International College Student project. A complete list of all within-country and cross-national WMH publications can be found at http://www.hcp.med.harvard.edu/wmh/.

\section{Compliance with ethical standards}

\section{Financial support}

The Belgium survey was supported by the Belgian Fund for Scientific Research (11N0514N/11N0516N/1114717N/1114719N), the King Baudouin Foundation (2014-J2140150-102905), Eli

Lilly (IIT-H6U-BX-I002), and Fonds GaVoorGeluk/ Diepensteyn Foundation (2018-LUF-0070). 


\section{Conflicts of interest}

In the past 3 years, Dr. Kessler received support for his epidemiological studies from Sanofi Aventis, he was a consultant for Johnson \& Johnson Wellness and Prevention, Shire and Takeda, and served on an advisory board for the Johnson \& Johnson Services Inc. Lake Nona Life Project. Dr. Kessler is a co-owner of DataStat, Inc., a market research firm that carries out healthcare research. Dr. Demyttenaere has served on advisory boards for Boehringer Ingelheim Eli Lilly, Lundbeck, Johnson\&Johnson, Livanova, Servier, and has research grants from Eli Lilly, foundation 'ga voor geluk', Fonds voor Wetenschappelijk Onderzoek Vlaanderen. Dr. Ebert reports to have received consultancy fees/served in the scientific advisory board from several companies such as Sanofi, Novartis, Minddistrict, Lantern, Schoen Kliniken, and German health insurance companies (BARMER, Techniker Krankenkasse). He is also a stakeholder of the Institute for health training online (GET.ON), which aims to implement scientific findings related to digital health interventions into routine care. The other authors have no interests to declare.

\section{Ethical Approval}

The study's protocol was approved by the University Hospital Leuven Biomedical Ethical Board and complies with the ethical standards of the Helsinki Declaration of 1975, as revised in 2008.

\section{Informed consent}

Informed consent was obtained from all students. 


\section{REFERENCES}

[1] Arnett JJ (2006) Emerging Adulthood: The Winding Road from the Late Teens through the Twenties. Emerg Adulthood Wind Road from Late Teens through Twenties 1-280.

https://doi.org/10.1093/acprof:oso/9780195309379.001.0001.

[2] Blanco C, Okuda M, Wright C, et al (2008) Mental health of college students and their non-collegeattending peers: Results from the national epidemiologic study on alcohol and related conditions. Arch Gen Psychiatry 65:1429-37. https://doi.org/10.1001/archpsyc.65.12.1429.

[3] Eisenberg D, Hunt J, Speer N (2013) Mental health in american colleges and universities: Variation across student subgroups and across campuses. J Nerv Ment Dis 201:60-7. https://doi.org/10.1097/NMD.0b013e31827ab077.

[4] Auerbach RP, Mortier R, Bruffaerts J, et al (2018) WHO World Mental Health Surveys International College Student Project: prevalence and distribution of mental disorders. J Abnorm Psychol 127:623. https://doi.org/ 10.1037/abn0000362.

[5] Bruffaerts R, Mortier P, Kiekens G, et al (2018) Mental health problems in college freshmen: Prevalence and academic functioning. J Affect Disord 225:97-103. https://doi.org/10.1016/j.jad.2017.07.044.

[6] Auerbach RP, Alonso J, Axinn WG, et al (2016) Mental disorders among college students in the World Health Organization World Mental Health Surveys. Psychol Med 46:2955-70. https://doi.org/10.1017/S0033291716001665.

[7] GBD 2016 Alcohol and Drug Use Collaborators (2018) The global burden of disease attributable to alcohol and drug use in 195 countries and territories, 1990-2016: a systematic analysis for the Global Burden of Disease Study 2016. The Lancet Psychiatry 5:987-1012. https://doi.org/10.1016/S22150366(18)30337-7.

[8] Pulay AJ, Dawson DA, Hasin DS, et al (2008) Violent behavior and DSM-IV psychiatric disorders: Results from the national epidemiologic survey on alcohol and related conditions. J Clin Psychiatry 69:12-22.https:// doi.org/10.4088/jcp.v69n0103.

[9] Hingson RW, Zha W, Weitzman ER (2009) Magnitude of and trends in alcohol-related mortality and morbidity among U.S. college students ages 18-24, 1998-2005. J Stud Alcohol Drugs Suppl 12-20. https://doi.org/10.15288/jsads.2009.s16.12.

[10] Jackson C, Geddes R, Haw S, Frank J (2012) Interventions to prevent substance use and risky sexual behaviour in young people: A systematic review. Addiction 107:733-47. https://doi.org/10.1111/j.13600443.2011.03751.x.

[11] Nichols LR, Samek DR, McConnell L (2019) Key personality traits and alcohol use disorder symptoms in first and second year college students: detangling antecedent from consequence. Addict Behav 89:178-87. https://doi.org/10.1016/j.addbeh.2018.10.004.

[12] van Zoonen K, Buntrock C, Ebert DD, et al (2014) Preventing the onset of major depressive disorder: A meta-analytic review of psychological interventions. Int J Epidemiol 43:318-29. https://doi.org/10.1093/ije/dyt175.

[13] Grant BF, Goldstein RB, Chou SP, et al (2009) Sociodemographic and psychopathologic predictors of first incidence of DSM-IV substance use, mood and anxiety disorders: Results from the Wave 2 National Epidemiologic Survey on Alcohol and Related Conditions. Mol Psychiatry 14:1051-66. https://doi.org/10.1038/mp.2008.41.

[14] Harrer M, Adam SH, Baumeister H, et al (2019) Internet interventions for mental health in university students: A systematic review and meta-analysis. Int J Methods Psychiatr Res 28. https://doi.org/10.1002/mpr.1759.

[15] Ebert DD, Mortier P, Kaehlke F, et al (2019) Barriers of mental health treatment utilization among firstyear college students: First cross-national results from the WHO World Mental Health International College Student Initiative. Int J Methods Psychiatr Res 28. https://doi.org/10.1002/mpr.1782. 
[16] Ganz T, Braun M, Laging M, Schermelleh-Engel K, Michalak J, Heidenreich T (2018) Effects of a stand-alone web-based electronic screening and brief intervention targeting alcohol use in university students of legal drinking age: A randomized controlled trial. Addict Behav 77:81-8. https://doi.org/10.1016/j.addbeh.2017.09.017.

[17] Ebert DD, Franke M, Kählke F, et al (2019) Increasing intentions to use mental health services among university students. Results of a pilot randomized controlled trial within the World Health Organization's World Mental Health International College Student Initiative. Int J Methods Psychiatr Res 28. https://doi.org/10.1002/mpr.1754.

[18] Hallfors D, Brodish PH, Khatapoush S, Sanchez V, Cho H, Steckler A (2006) Feasibility of screening adolescents for suicide risk in "real-world" high school settings. Am J Public Health 96:282-7. https://doi.org/10.2105/AJPH.2004.057281.

[19] Kiekens G, Hasking P, Claes L, et al (2019) Predicting the incidence of non-suicidal self-injury in college students. Eur Psychiatry 59:44-51. https://doi.org/10.1016/j.eurpsy.2019.04.002.

[20] Ebert DD, Buntrock C, Mortier P, et al (2018) Prediction of major depressive disorder onset in college students. Depress Anxiety 36:294-304. https://doi.org/10.1002/da.22867

[21] Mortier P, Demyttenaere K, Auerbach RP, et al (2017) First onset of suicidal thoughts and behaviours in college. J Affect Disord 207:291-9. https://doi.org/10.1016/j.jad.2016.09.033.

[22] Ebert DD, Cuijpers P, Muñoz RF, Baumeister H (2017) Prevention of mental health disorders using internet- and mobile-based interventions: A narrative review and recommendations for future research. Front Psychiatry 8. https://doi.org/10.3389/fpsyt.2017.00116.

[23] Ribeiro JD, Franklin JC, Fox KR, et al (2016) Self-injurious thoughts and behaviors as risk factors for future suicide ideation, attempts, and death: a meta-analysis of longitudinal studies. Psychol Med 46:225-36. https://doi.org/10.1017/S0033291715001804.

[24] Saunders JB, Aasland OG, Babor TF, De La Fuente JR, Grant M (1983) Development of the Alcohol Use Disorders Identification Test (AUDIT): WHO Collaborative Project on Early Detection of Persons with Harmful Alcohol Consumption-II. Addiction 88:791-804. https://doi.org/10.1111/j.13600443.1993.tb02093.x.

[25] Babor TF, Higgins-Biddle JC, Saunders JB, Monteiro MG (2001) The Alcohol Use Disorders Identification Test Guidelines for Use in Primary Health Care. World Health Organization. Geneva, Switz. http://apps.who.int/iris/handle/10665/67205

[26] Reinert DF, Allen JP (2002) The alcohol use disorders identification test (AUDIT): A review of recent research. Alcohol Clin Exp Res 26:272-9. https://doi.org/10.1111/j.1530-0277.2002.tb02534.x.

[27] Lange S, Shield K, Monteiro M, Rehm J. (2019). Facilitating Screening and Brief Interventions in Primary Care: A Systematic Review and Meta-Analysis of the AUDIT as an Indicator of Alcohol Use Disorders. Alcohol Clin Exp Res 43:2028-2037. https://doi:10.1111/acer.14171

[28] Australian Government Department of Veteran Affairs.

[29] Kessler RC, Üstün BB (2004) The World Mental Health (WMH) Survey Initiative version of the World Health Organization (WHO) Composite International Diagnostic Interview (CIDI). Int J Methods Psychiatr Res 13:93-117. https://doi.org/10.1002/mpr.168.

[30] Felitti VJ, Anda RF, Nordenberg D, et al (1998) Relationship of childhood abuse and household dysfunction to many of the leading causes of death in adults: the Adverse Childhood Experiences (ACE) Study. Am J Prev Med 14:245-258. https://doi.org/10.1016/s0749-3797(98)00017-8.

[31] Swearer SM, Cary PT. (2003) Perceptions and Attitudes Toward Bullying in Middle School Youth. J Appl Sch Psychol 19:63-79. https://doi.org/10.1300/j008v19n02_05.

[32] Nansel TR, Overpeck M, Pilla RS, Ruan WJ, Simons-Morton B, Scheidt P. (2001) Bullying behaviors among US youth: Prevalence and association with psychosocial adjustment. J Am Med Assoc 285:2094100. https://doi.org/10.1001/jama.285.16.2094.

[33] Brugha TS, Cragg D (1990) The List of Threatening Experiences: the reliability and validity of a brief 
life events questionnaire. Acta Psychiatr Scand 82:77-81. https://doi.org/10.1111/j.16000447.1990.tb01360.x.

[34] Bray RM, Hourani LL (2007) Substance use trends among active duty military personnel: Findings from the United States Department of Defense Health Related Behavior Surveys, 1980-2005. Addiction 102:1092-101. https://doi.org/10.1111/j.1360-0443.2007.01841.x.

[35] Vogt DS, Proctor SP, King DW, King LA, Vasterling JJ (2008) Validation of scales from the deployment risk and resilience inventory in a sample of operation \{Iraqi\} freedom veterans. Assessment 15:391-403. https://doi.org/10.1177/1073191108316030

[36] Stoeckel M, Weissbrod C (2015) Growing up with an ill parent: An examination of family characteristics and parental illness features. Fam Syst Heal 33:356-62. https://doi.org/10.1037/fsh0000140.

[37] Rostila M, Berg L, Arat A, Vinnerljung B, Hjern A (2016) Parental death in childhood and self-inflicted injuries in young adults-a national cohort study from Sweden. Eur Child Adolesc Psychiatry 25:110311. https://doi.org/10.1007/s00787-016-0833-6.

[38] Buitron V, Hill RM, Pettit JW, Green KL, Hatkevich C, Sharp C (2016) Interpersonal stress and suicidal ideation in adolescence: An indirect association through perceived burdensomeness toward others. $\mathrm{J}$ Affect Disord 190:143-9. https://doi.org/10.1016/j.jad.2015.09.077.

[39] Trotman GE, Young-Anderson C, Deye KP (2016) Acute Sexual Assault in the Pediatric and Adolescent Population. J Pediatr Adolesc Gynecol 29:518-26. https://doi.org/10.1016/j.jpag.2015.05.001.

[40] Viswanathan S, Datta S, Sheridan P, Lax-Pericall T (2014) “Too young to be worried!" Psychiatric assessment and follow-up of young people after severe physical assault in an Inner City Hospital of South London. Ann Med Health Sci Res 4:85-9. https://doi.org/10.4103/2141-9248.126607.

[41] Salekin RT (2008) Psychopathy and Recidivism From Mid-Adolescence to Young Adulthood: Cumulating Legal Problems and Limiting Life Opportunities. J Abnorm Psychol 117:386-95. https://doi.org/10.1037/0021-843X.117.2.386.

[42] Kessler RC, Santiago PN, Colpe LJ et al (2013) Clinical reappraisal of the Composite International Diagnostic Interview Screening Scales (CIDI-SC) in the Army Study to Assess Risk and Resilience in Servicemembers (Army STARRS). Int J Methods Psychiatr Res 22:303-21. https://doi.org/10.1002/mpr.1398.

[43] Nock MK, Holmberg EB, Photos VI, Michel BD (2007) Self-Injurious Thoughts and Behaviors Interview: Development, Reliability, and Validity in an Adolescent Sample. Psychol Assess 19:309-17. https://doi.org/10.1037/1040-3590.19.3.309.

[44] Sheehan DV, Lecrubier Y, Sheehan KH, et al (1998) The Mini-International Neuropsychiatric Interview (M.I.N.I.): the development and validation of a structured diagnostic psychiatric interview for DSM-IV and ICD-10. J Clin Psychiatry 59:22-3.

[45] Rosenbaum PR, Rubin DB (1983) The central role of the propensity score in observational studies for causal effects. Biometrica 70:41-55. https://doi.org/10.1093/biomet/70.1.41

[46] van Buuren S (2007) Multiple imputation of discrete and continuous data by fully conditional specification. Stat Methods Med Res 16:219-42. https://doi.org/10.1177/0962280206074463.

[47] Efron, B, Gond G (1983) A Leisurely Look at the Bootstrap , the Jackknife, and Cross-Validation. Am Stat 37:36-48. https://doi.org/10.2307/2685844

[48] Barendregt JJ, Veerman JL (2010) Categorical versus continuous risk factors and the calculation of potential impact fractions. J Epidemiol Community Health 64:209-12. https://doi.org/10.1136/jech.2009.090274.

[49] Prince MA, Read JP, Colder CR (2019) Trajectories of College Alcohol Involvement and Their Associations with Later Alcohol Use Disorder Symptoms. Prev Sci 20:741-52. https://doi.org/10.1007/s11121-018-0974-6.

[50] Read JP, Colder CR, Merrill JE, Ouimette P, White J, Swartout A (2012) Trauma and posttraumatic stress symptoms predict alcohol and other drug consequence trajectories in the first year of college. $\mathrm{J}$ Consult Clin Psychol 80:426-39. https://doi.org/10.1037/a0028210. 
[51] Meisel MK, Barnett NP (2017) Protective and risky social network factors for drinking during the transition from high school to college. J Stud Alcohol Drugs 78:922-9. https://doi.org/10.15288/jsad.2017.78.922.

[52] Fleming CB, White HR, Oesterle S, Haggerty KP, Catalano RF (2010) Romantic relationship status changes and substance use among 18- to 20-year-olds. J Stud Alcohol Drugs 71:847-56. https://doi.org/10.15288/jsad.2010.71.847

[53] Paul E, Tsypes A, Eidlitz L, Ernhout C, Whitlock J (2015) Frequency and functions of non-suicidal selfinjury: Associations with suicidal thoughts and behaviors. Psychiatry Res 225:276-82. https://doi.org/10.1016/j.psychres.2014.12.026.

[54] Kessler R, Farley P, Gruber M et al (2010) Concordance of computerized self-report measures of DSMIV-Tr mood and anxiety disorders compared to gold standard clinical assessments in primary care. Atlanta, Georgia: International Society for Pharmacoeconomics and Outcomes Research 15th Annual International Meeting.

[55] Meque I, Salom C, Betts KS, Alati R (2019) Predictors of Alcohol Use Disorders Among Young Adults: A Systematic Review of Longitudinal Studies. Alcohol Alcohol 54:310-24.

https://doi.org/10.1093/alcalc/agz020.

[56] Berking M, Margraf M, Ebert D, Wuppermann P, Hofmann S, Junghanns K (2011) Deficits in emotionregulation skills predict alcohol use during and after cognitive-behavioral therapy for alcohol dependence. J Consult Clin Psychol 79:307-18.

[57] Scott-Sheldon LAJ, Carey KB, Elliott JC, Garey L, Carey MP (2014) Efficacy of alcohol interventions for first-year college students: A meta-analytic review of randomized controlled trials. J Consult Clin Psychol 82:177-88. https://doi.org/10.1037/a0035192.

[58] Hennessy EA, Tanner-Smith EE, Mavridis D, Grant SP (2019) Comparative Effectiveness of Brief Alcohol Interventions for College Students: Results from a Network Meta-Analysis. Prev Sci 20:715-40. https://doi.org/10.1007/s11121-018-0960-z.

[59] Turrisi R, Larimer M, Mallett K, et al (2009) A randomized clinical trial evaluating a combined alcohol intervention for high-risk college students. J Stud Alcohol Drugs 70:555-67. https://doi.org/ 10.15288/jsad.2009.70.555.

[60] Kazdin AE (2018) Innovations in psychosocial interventions and their delivery: Leveraging cutting-edge science to improve the world's mental health. Innov Psychosoc Interv Their Deliv Leveraging CuttingEdge Sci to Improv World's Ment Heal. https://doi.org/http://dx.doi.org/10.1093/medpsych/9780190463281.001.0001.

[61] Riper H, Hoogendoorn A, Cuijpers P, et al (2018) Effectiveness and treatment moderators of internet interventions for adult problem drinking: An individual patient data meta-analysis of 19 randomised controlled trials. PLoS Med 15. https://doi.org/10.1371/journal.pmed.1002714.

[62] Sundström C, Blankers M, Khadjesari Z (2017) Computer-Based Interventions for Problematic Alcohol Use: a Review of Systematic Reviews. Int J Behav Med 24:646-58. https://doi.org/10.1007/s12529-0169601-8.

[63] Bhochhibhoya A, Hayes L, Branscum P, Taylor L (2015) The use of the internet for prevention of binge drinking among the college population: A systematic review of evidence. Alcohol Alcohol 50:526-35. https://doi.org/10.1093/alcalc/agv047.

[64] Carey KB, Scott-Sheldon LA, Elliott JC, Garey L, Carey MP (2012) Face-to-face versus computerdelivered alcohol interventions for college drinkers: a meta-analytic review, 1998 to 2010. Clin Psychol Rev 32:690-703. https://doi.org/10.1016/j.cpr.2012.08.001

[65] Kypri K, Vater T, Bowe SJ, et al (2014) Web-based alcohol screening and brief intervention for university students: A randomized trial. JAMA - J Am Med Assoc 311:1218-24.

https://doi.org/10.1001/jama.2014.2138. 